The Journal of Experimental Biology 209, 1064-1073

Published by The Company of Biologists 2006

doi: $10.1242 /$ jeb.02129

\title{
The relative contributions of developmental plasticity and adult acclimation to physiological variation in the tsetse fly, Glossina pallidipes (Diptera, Glossinidae)
}

\author{
John S. Terblanche ${ }^{1, *}$ and Steven L. Chown ${ }^{2}$ \\ ${ }^{1}$ Spatial, Physiological and Conservation Ecology Group, Department of Botany and Zoology, University of \\ Stellenbosch, Private Bag X1, Matieland, 7602, Stellenbosch, South Africa and ${ }^{2}$ Centre for Invasion Biology, \\ University of Stellenbosch, Private Bag X1, Matieland, 7602, Stellenbosch, South Africa
}

*Author for correspondence (e-mail: jst@sun.ac.za)

Accepted 26 January 2006

\begin{abstract}
Summary
Recent reviews of the adaptive hypotheses for animal responses to acclimation have highlighted the importance of distinguishing between developmental and adult (nondevelopmental) phenotypic plasticity. There has been little work, however, on separating the effects of developmental plasticity from adult acclimation on physiological traits. Therefore, we investigated the relative contributions of these two distinct forms of plasticity to the environmental physiology of adult tsetse flies by exposing developing pupae or adult flies to different temperatures and comparing their responses. We also exposed flies to different temperatures during development and reexposed them as adults to the same temperatures, to investigate possible cumulative effects. Critical thermal

temperature accounting for most of the variance (84-92\%). Surprisingly little of the variance in desiccation rate could be explained by plasticity type $(30-47 \%)$. The only significant effect of acclimation temperature on standard (resting) metabolic rate of adult flies was at $21^{\circ} \mathrm{C}$, resulting in treatment temperature, rather than plasticity type, accounting for the majority of the variance (30-76\%). This study demonstrates that the stage at which acclimation takes place has significant, though often different, effects on several adult physiological traits in $\boldsymbol{G}$. pallidipes, and therefore that it is not only important to consider the form of plasticity but also the direction of the response and its significance from a life-history perspective.
\end{abstract} maxima were relatively inflexible in response to acclimation temperatures $\left(21,25,2^{\circ} \mathrm{C}\right)$ with plasticity type accounting for the majority of the variation (49-67\%, nested ANOVA). By contrast, acclimation had a larger effect on critical thermal minima with treatment
Key words: intra-specific variation, metabolic rate, phenotypic plasticity, water balance, beneficial acclimation hypothesis, climatic stress resistance, tsetse fly.

\section{Introduction}

Recently, interest in the nature and magnitude of nongenetic effects on phenotypic variation has increased. Phenotypic plasticity might not only account for much of the variation among populations (Ayrinhac et al., 2004; Hoffmann et al., 2005b), but could also significantly affect the nature of evolutionary responses of populations (Price et al., 2003) and their likely survival, especially in the face of rapidly changing modern climates (Helmuth et al., 2005; Somero, 2005). Physiologists have long assumed that acclimation (or acclimatization, both are forms of plasticity) to a particular environment enhances performance in that environment (e.g. Hochachka and Somero, 2002; Prosser, 1986) such that acclimation is beneficial (see Leroi et al., 1994). However, in recent years the generality of this beneficial acclimation hypothesis has been questioned because most formal tests of the predictions thereof have been negative (Gibert et al., 2001; Gilchrist and Huey, 2001; Leroi et al., 1994; Sibly et al., 1997; Woods, 1999; Woods and Harrison, 2001; Zamudio et al., 1995) (but see Nunney and Cheung, 1997; Thomson et al., 2001). Subsequently, Wilson and Franklin (Wilson and Franklin, 2002) argued that many of these tests actually addressed the adaptive significance of developmental plasticity rather than of acclimation. That is, the tests examined the consequences for the adult phenotype of altered rearing environments, rather than the consequences of environmental variation within a given life-stage, and more specifically, the adults. Therefore, they should not be considered tests of the beneficial acclimation hypothesis because acclimation is typically defined as a reversible, facultative response to changes in the adult environment (Spicer and Gaston, 1999; Wilson and Franklin, 2002). Given the wide range of conditions under which adaptive phenotypic plasticity is thought to arise 


\section{Plasticity in tsetse flies}

(Berrigan and Scheiner, 2004; Scheiner, 1993), these alternative perspectives on beneficial acclimation have proven controversial.

One outcome of the debate is the realization that few studies have sought to examine the effects of acclimation in the rearing stage (developmental plasticity) relative to those in the adult or within a given life-stage (adult acclimation, sometimes also known as phenotypic flexibility) (see Piersma and Drent, 2003), and the nature of the interactions between them. The most detailed work to date has been that of Fischer and coworkers (Fischer et al., 2003; Zeilstra and Fischer, 2005). In the first study (Fischer et al., 2003), rearing temperature had a substantial effect on the size of eggs laid by Bicyclus anynana butterflies. However, these effects were largely reversible after adults were held at different temperatures. Thus, the magnitude of the developmental plasticity and adult acclimation effects was similar. The second study (Zeilstra and Fischer, 2005) used Lycaena tityrus and again found that the effects of developmental plasticity on recovery time from cold shock were largely reversible. They also found that as long as newly eclosed adults were not exposed to cold shock, adult temperatures (i.e. an adult exposure and a rearing exposure to different temperatures) also affected recovery time, though these times tended to be shorter than those for butterflies exposed to cold shock immediately after eclosion (i.e. a rearing exposure only). Few other studies of this nature have been undertaken (though for discussion of early work, see Spicer and Gaston, 1999; and see Tracy and Walsberg, 2001), and therefore their generality is not certain.

In this study we therefore examine the effects of altering treatment temperatures during pupal development (developmental plasticity), during the adult stage (adult acclimation) and during both stages (combined plasticity) on four traits, viz. critical thermal minimum and maximum, water loss rate and metabolic rate, in the tsetse fly Glossina pallidipes Austen. This species was chosen for several reasons. First, variation in the traits of interest across the Insecta is typically partitioned at family and order levels (Chown et al., 2002). Therefore, investigations of non-lepidopteran species are likely to provide a rapid way of determining how general previous findings are likely to be. Second, temperature and water availability are important correlates of the distribution of $G$. pallidipes and play major roles in influencing its population dynamics directly (Hargrove, 2004; Rogers and Robinson, 2004) and indirectly via metabolic rate (Bursell et al., 1974; Bursell and Taylor, 1980; Terblanche et al., 2004). Investigating the mechanistic bases of the responses of flies to their external environment is therefore a significant link in the causal chain of reasoning from environment to population dynamics. Finally, as a vector of animal disease, G. pallidipes has important effects on animal health, and thus indirect effects upon socio-economic development in Africa (Maudlin et al., 2004). Understanding the likely current and future determinants of its abundance and distribution is therefore of considerable significance for ongoing development of the continent (Maudlin et al., 2004).

\section{Materials and methods}

Laboratory conditions and maintenance

Glossina pallidipes Austen (Diptera, Glossinidae) puparia 12-13 days old (hereafter pupae) were received from a laboratory colony maintained at the Entomology Unit, FAO/IAEA Agriculture and Biotechnology Laboratory, Seibersdorf, International Atomic Energy Agency, Vienna, Austria. It is unlikely that these experimental flies exhibited inbreeding depression or other deleterious genetic effects of colonization because gene diversities over two mitochondrial loci were within the range of 18 field populations from Ethiopia, east and southern Africa (Krafsur and Wohlford, 1999). It is these pupae that were subjected to an acclimation treatment, or simply maintained close to the original conditions in which they were held at the Seibersdorf laboratory.

On arrival, pupae were immediately placed in Petri dishes ( $N=50$ per dish) on paper towels, which were stored inside two plastic containers with non-airtight lids and transferred to a climate chamber held at $25^{\circ} \mathrm{C}$ (mean \pm s.d.: $24.8 \pm 1.0$ ). They were retained at this temperature except in the case of the developmental plasticity treatments, in which pupae were moved to incubators set at either $21^{\circ} \mathrm{C}$ or $29^{\circ} \mathrm{C}$ (see below), but otherwise identical to those described here. Relative humidity (RH) inside containers was regulated by means of saturated salt $(\mathrm{NaCl})$ solutions located within each container to give 76\% RH (Winston and Bates, 1960). At the first sign of eclosion, pupae were transferred to $10-12$ mesh cages $(10 \mathrm{~cm}$ diameter, $N<50$ per cage) and either retained at the original temperature or moved later to a different temperature for an adult acclimation treatment (details below). Cages were stored inside closed, non-airtight plastic containers with relative humidity regulated as above.

The adults were fed using a membrane-tray system (see Gooding et al., 1997) every alternate day, similar to the methods described elsewhere (Terblanche et al., 2004), and subsequently container locations were randomized within climate chambers. Care was taken to ensure that all treatment groups were handled for the same duration during transfer from the climate chamber to the feeding area, and spent a similar amount of time outside of the climate chambers whilst feeding ( 25 min per group). Temperatures during shipment and acclimation were recorded using Thermocron iButtons (Dallas Semiconductors, Dallas, Texas, USA; sampling rate $=15 \mathrm{~min}$; temperature during shipment: $24.2 \pm 2.9^{\circ} \mathrm{C}$, mean \pm s.d.).

\section{Treatments}

Three experimental treatments were undertaken: a developmental plasticity treatment, involving manipulation of the temperatures that the pupae experienced; an adult acclimation treatment in which pupae developed at a common temperature, but adults were exposed to different temperatures; and a combined treatment where both pupae and adults were exposed to a given temperature (Fig. 1). In the case of developmental plasticity the following protocol was followed: Pupae received a 6-day acclimation in climate chambers set to $21^{\circ} \mathrm{C}$ (mean \pm s.d.: $20.5 \pm 1.0^{\circ} \mathrm{C}$ ), and $29^{\circ} \mathrm{C}\left(28.0 \pm 0.2^{\circ} \mathrm{C}\right.$ ) 


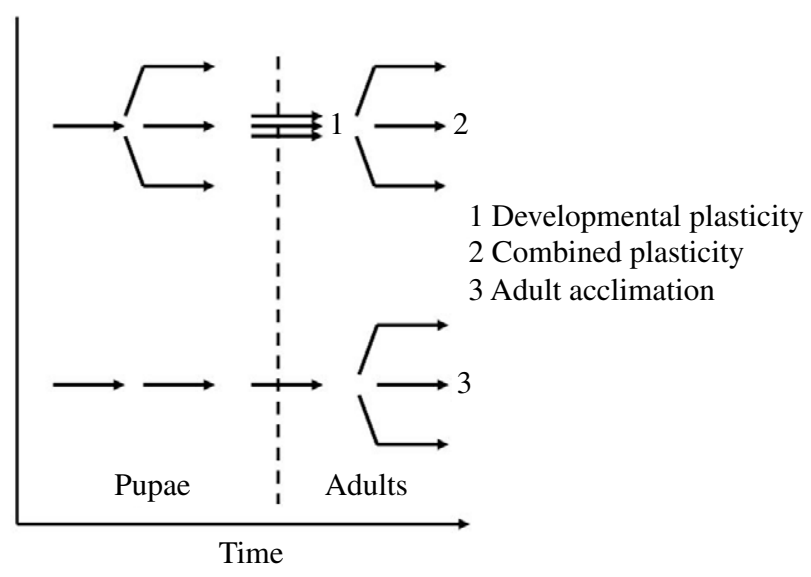

Fig. 1. Schematic diagram of the experimental design used to investigate the relative contribution of developmental plasticity (1), adult acclimation (3) and combined treatment (2) to adult physiological performance in Glossina pallidipes. (Broken line represents eclosion.)

starting approximately 12-13 days prior to the expected date of emergence (i.e. just over halfway through the pupal stage). Pupae were also kept at $25^{\circ} \mathrm{C}$, though handled in the same way as the other groups, to provide insight into the changes relative to baseline conditions (for rationale, see Sinclair and Chown, 2005). After 6 days of acclimation, all groups were returned to $25^{\circ} \mathrm{C}$ for emergence. This treatment does not constitute a full rearing exposure (as in Fischer et al., 2003), but nonetheless has a marked effect on the pupae (as confirmed in pilot trials). Moreover, it was undertaken because the time course of critical thermal minima $T_{\text {crit,min }}$ has been examined in adult $G$. pallidipes previously. This revealed that a maximum response is typically obtained within 5 days of exposure, and does not reflect a graded (temperature-dependent) response, but rather demonstrates a distinct temperature threshold (Terblanche et al., in press). Eclosion commenced in the warmest acclimation group c. 7-8 days before the coolest acclimation group. Thus, depending on the experimental temperature in each developmental plasticity group, a total of 12-19 days passed between the end of the acclimation period and the onset of the experimental assessments. For G. pallidipes, 10 days at $25^{\circ} \mathrm{C}$ is sufficient to completely reverse adult acclimation responses in $T_{\text {crit,min }}$ after 9 days at $19-21^{\circ} \mathrm{C}$ (i.e. adult acclimation responses for this trait were reversible) (Terblanche et al., in press). After 30-40\% of the flies in an experimental group had begun to eclose, flies were taken through three blood meals, or 'hunger cycles' ( 6 days), and used for experimental assessment on approximately the eighth day of the adult stage in a fasted, post-developmental (non-teneral) state. This group was considered the 'developmental plasticity' treatment (Fig. 1).

On the day following the experimental assessment, the remaining flies were fed as usual and were then transferred back to the same temperature received during the pupal stage (e.g. flies which were exposed to $21^{\circ} \mathrm{C}$ during the pupal stage were returned to $21^{\circ} \mathrm{C}$ ) and left to acclimate for a further 6 days, whereupon the same physiological measures were assessed. These flies were labelled the "combined plasticity' treatment (Fig. 1). Preliminary experiments using $T_{\text {crit,min }}$ in adult $G$. pallidipes showed that acclimation responses can be fully induced after 6 days and $T_{\text {crit,min }}$ does not change further with longer duration of acclimation (up to 12 days) (Terblanche et al., in press).

The final treatment was the adult acclimation treatment (Fig. 1). Pupae left at $25^{\circ} \mathrm{C}\left(24.8 \pm 1.0^{\circ} \mathrm{C}\right)$ until after eclosion were divided into groups and placed in climate chambers set to 21,25 and $29^{\circ} \mathrm{C}$. The flies were switched to these cabinets on day 6 after three hunger cycles (as above), and left at these temperatures for 6 days before traits were assessed.

\section{Experimental assessments}

All experimental assessments were performed on adult flies. In each experiment, care was taken to randomly select flies from as many cages as possible. In cases where the number of flies required was higher than the number of available cages, fly selection was balanced among cages. In addition, all acclimation groups were handled with similar duration and vigour. Although no cage $\times$ treatment effects could be detected in preliminary experiments (Terblanche et al., in press), the present treatments, in conjunction with frequently randomized cage locations, probably prevented any significant cage $\times$ treatment interactions.

\section{Critical thermal limits}

An insulated system with eleven double-jacketed isolation chambers was connected to a programmable water bath (LTD 20 with PZ1 programmer, Grant Instruments, Cambridge, UK), which regulated water flow around the chambers. A single fly was placed in each of the ten chambers. A 40 SWG type-T thermocouple was inserted into a control chamber to measure chamber temperatures. The flies were allowed to equilibrate for $10 \mathrm{~min}$ at either 12 or $35^{\circ} \mathrm{C}$ before the commencement of the respective minimum and maximum critical thermal limit assessments. Because of their small body mass, the body temperature of flies was considered equivalent to the chamber temperature. Moreover, there is no significant difference between body temperature and ambient temperature across the range $25-45^{\circ} \mathrm{C}$ under high humidity conditions in G. morsitans (Edney and Barrass, 1962). After equilibration, the chamber's temperature was decreased or increased at a rate of $0.25^{\circ} \mathrm{C} \mathrm{min}{ }^{-1}$. Critical thermal minima $\left(T_{\text {crit,min }}\right)$ were defined as the loss of coordinated muscle function at decreasing temperatures and critical thermal maxima $\left(T_{\text {crit,max }}\right)$ as the onset of muscle spasms at increasing temperatures (Klok and Chown, 1998). These endpoints are readily identifiable for any species once an observer is practiced (Lutterschmidt and Hutchison, 1997). Typically the variance about the endpoints is low, and here a single observer (C. J. Klok) undertook all of this work. Moreover, this experimental procedure has been verified using thermolimit respirometry (Klok et al., 2004), is widely used to assess thermal limits (Chown and Nicolson, 
2004), and the observer typically was not informed which acclimation treatment was being assessed. Groups of ten flies were assessed together and the temperature at which these limits were observed was recorded for each individual fly. Preliminary experiments using adult flies found no effect of gender, age or feeding status on critical thermal limits (C. J. Klok and J. S. Terblanche, unpublished data), and we assumed that this was also the case in the present study.

\section{Desiccation rate}

To remove possible confounding effects of sex or pregnancy, only male flies were used in desiccation experiments. Flies $(N=16)$, individually contained in $5 \mathrm{ml}$ cuvettes, were subjected to desiccation in flowing air $(<2.5 \%$ $\mathrm{RH}$ ) for $10 \mathrm{~h}$ at $25.0 \pm 1.0^{\circ} \mathrm{C}$ in a climate chamber (Labotech, Pretoria, South Africa). Air flow, produced by an aquarium pump, was directed through a scrubbing column containing silica gel and Drierite (Xenia, OH, USA) as desiccants to remove residual water, and then into a mass flow-controller to control the air flow rate. The mass flow-controller outlet was connected to a Sable Systems (Las Vegas, NV, USA) MF8 airflow manifold. Each outflow channel of the manifold was further split in two so that two cuvettes, each containing a fly, were attached per manifold channel. The air flow rate through each cuvette, tested using a second mass flow-controller, was regulated to $100 \mathrm{ml} \mathrm{min}^{-1}$. Experiments took place during the night (21:00 h-07:00 h) because this represents a period of minimal activity in tsetse (Brady, 1988; Kyorku and Brady, 1993). Mass was recorded before and after an experiment using an electronic microbalance $(0.1 \mathrm{mg}$, Avery Berkel FA 304T, EU, Fairmont, MN, USA) and the difference was assumed to be a result of water loss (acknowledging that some mass loss is due to substrate catabolism but that this is negligible relative to the quantity of water loss over the time scales investigated here (Bursell, 1957)). Flies were dried to constant mass $\left(\sim 50-60^{\circ} \mathrm{C}\right.$ for $\left.\sim 72 \mathrm{~h}\right)$ and re-weighed to give dry body mass.

\section{Metabolic rate}

Metabolic rate was recorded using flow-through respirometry. A calibrated LI-6262 (LiCor; Lincoln, NN, USA) infra-red gas analyzer (IRGA) was connected to a Sable Systems eight channel multiplexer inside a temperaturecontrolled cabinet, as described previously (Terblanche et al., 2004). The first seven channels regulated the flow-through respirometry for individual flies and channel eight was used as an empty reference channel for $\mathrm{CO}_{2}$ and $\mathrm{H}_{2} \mathrm{O}$ baseline measurements. These recordings were performed for fasted, post-development males at $25^{\circ} \mathrm{C}$ in each acclimation group. Mass was recorded before and after respirometry recordings as described in the desiccation experiments. Airflow was regulated to $100 \mathrm{ml} \mathrm{min}^{-1}$ using a mass flow-controller and the outside air was scrubbed through sodalime, silica-gel and Drierite columns to remove water and $\mathrm{CO}_{2}$. A Sable Systems $\mathrm{AD}-1$ activity detector was connected to the first cuvette only to compare active and resting gas exchange traces in all flies. Previous studies have shown that in this species activity can be reliably detected from the $\dot{V}_{\mathrm{CO}_{2}}$ trace without an activity detection system (Terblanche et al., 2004), which was confirmed here. Sable Systems Datacan V software was used to extract and analyze standard (resting) metabolic rate (SMR) data from 5-8 individuals per treatment group.

\section{Statistical analyses}

For all traits, the effect of the treatment $\left(21\right.$ or $\left.29^{\circ} \mathrm{C}\right)$ relative to the standard rearing conditions $\left(25^{\circ} \mathrm{C}\right)$ was assessed. One way analyses of variance (ANOVA) followed by post-hoc tests for homogeneity were used to compare the three temperature groups in the case of $T_{\text {crit,min }}$ and $T_{\text {crit,max }}$. Because body mass influences both metabolic rate and water loss rate (AddoBediako et al., 2001; Addo-Bediako et al., 2002) analyses of covariance were used for these traits. These analyses provided primary insight into the effects of developmental plasticity, adult acclimation, and the combined treatment. However, to assess the relative contributions of plasticity type and treatment temperature to trait variation, two pure Model II (random effects) nested ANOVAs were undertaken (Sokal and Rohlf, 1995, p. 274). In the first analysis, treatment temperature was nested within plasticity type using data for developmental plasticity and adult acclimation only. In the second analysis, all three plasticity types were assessed nested within treatment temperature. These two nested ANOVAs present complimentary perspectives on the relative importance of plasticity type and treatment temperature for variation in each of the traits. Previous work demonstrated that the effects of developmental plasticity can be altered following adult acclimation for several traits (Fischer et al., 2003; Zeilstra and Fischer, 2005). Therefore we expected equal contributions of plasticity types to total variance. Sample sizes for physiological assessments ranged from 9-20 $\left(T_{\text {crit,max }}\right), 12-20$ ( $T_{\text {crit,min }}$ ), 8-16 (water balance) and 5-8 (metabolic rate) individuals per treatment per temperature.

\section{Results}

Differences in $T_{\text {crit,max }}$ associated with treatment temperature were small, irrespective of whether this treatment took place in the pupal or adult stages, and significant in one case of adult acclimation only (Fig. 2). Thus, much of the variance in $T_{\text {crit,max }}$ was explained by plasticity type (Table 1 ). The combined plasticity treatment tended to be most similar to the pupal treatment, and treatment temperature effects were small, resulting in plasticity type retaining its importance in the nested ANOVA including all three plasticity types (Table 2). Differences in $T_{\text {crit,min }}$ among treatment temperatures were much more pronounced (Fig. 3). The effect was largest in the case of adult acclimation and combined plasticity for the $21^{\circ} \mathrm{C}$ treatment, but in the $29^{\circ} \mathrm{C}$ treatment developmental plasticity (and combined plasticity) had the largest effects. Perhaps more significantly, the effects of the two treatment temperatures were opposite in sign. Thus, in both nested ANOVAs treatment temperature accounted for most of the variance (Tables 1 and 2). 


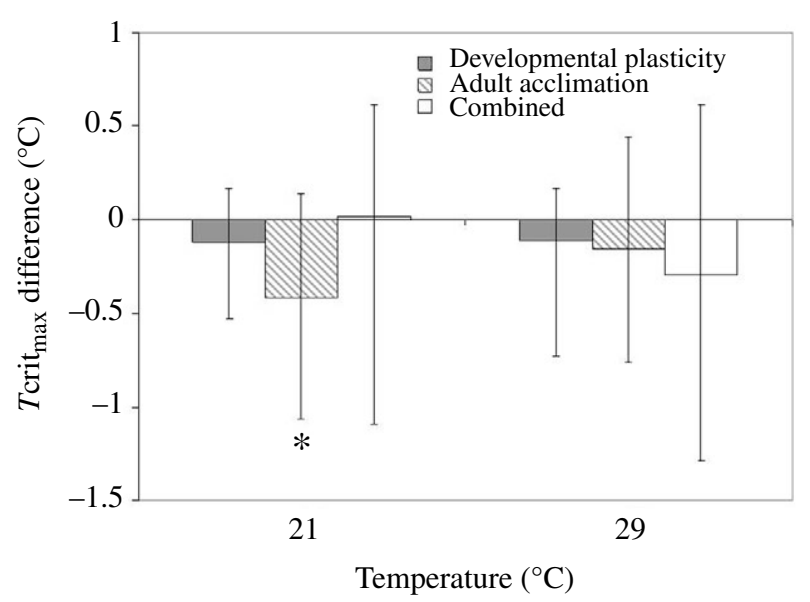

Fig. 2. Relative change in mean critical thermal maxima $T_{\text {crit,max }}$ for developmental plasticity, adult acclimation and combined plasticity groups within the acclimation temperature treatments, expressed as change from the mean of the $25^{\circ} \mathrm{C}$ group. Asterisks indicate a significant effect of the acclimation relative to the $25^{\circ} \mathrm{C}$ group by oneway ANOVA $(P<0.05)$. Lower and upper error bars represent minimum and maximum values, respectively.

Treatment temperature at the pupal stage had little effect on water loss rate, and this was also true for adult acclimation, except for a strong decline following adult acclimation at a treatment temperature of $29^{\circ} \mathrm{C}$ (Fig. 4). The combined plasticity treatment at $29^{\circ} \mathrm{C}$ also resulted in a substantial increase in water loss rate. In consequence, plasticity type explained a larger proportion of the variance when when all three plasticity types were included in the nested ANOVA (Table 2). However, surprisingly little of the variance in desiccation rate could be explained by plasticity type when

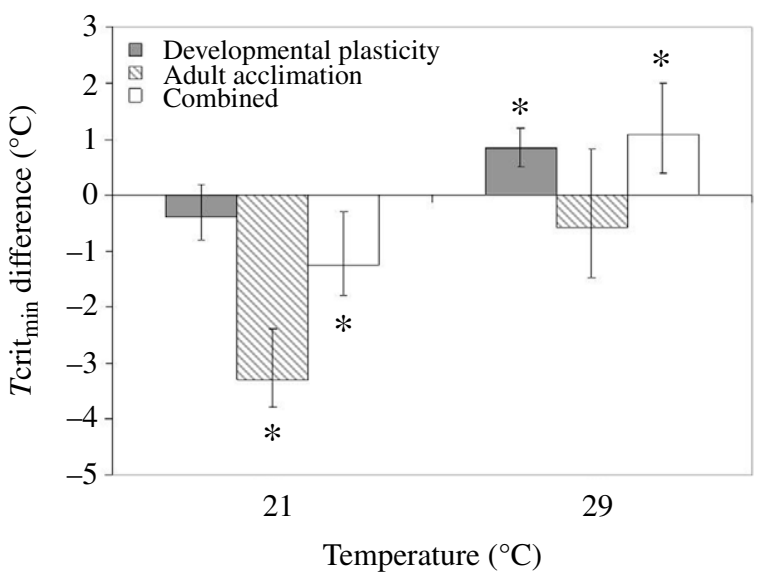

Fig. 3. Relative change in mean critical thermal minima $T_{\text {crit,min }}$ for developmental plasticity, adult acclimation and combined plasticity groups within the acclimation temperature treatments expressed as change from the mean of the $25^{\circ} \mathrm{C}$ group. Asterisks indicate a significant effect of the acclimation relative to the $25^{\circ} \mathrm{C}$ group by oneway ANOVA $(P<0.05)$. Lower and upper error bars represent minimum and maximum values, respectively.

only developmental plasticity and adult acclimation were considered (Table 1).

When only developmental plasticity and adult acclimation were considered, the only significant effect was a response of adult metabolic rate to the $21^{\circ} \mathrm{C}$ treatment (Fig. 5). In consequence, treatment temperature explained most of the variance (Table 1) among treatment temperature and plasticity type. This increase in metabolic rate following the $21^{\circ} \mathrm{C}$ treatment was also found when both adults and pupae were exposed to acclimation, resulting in a more even partitioning

Table 1. Testing for an effect of the plasticity type (developmental vs adult) and acclimation (treatment temperature $21,29^{\circ} \mathrm{C}$ ) on physiological traits of climatic stress resistance in adult Glossina pallidipes (Diptera, Glossinidae)

\begin{tabular}{|c|c|c|c|c|c|c|c|c|}
\hline Physiological trait & Effect & d.f. & MS & d.f. error & MS error & $F$-ratio & $P$ & $\begin{array}{l}\% \text { variance } \\
\text { explained }\end{array}$ \\
\hline $\begin{array}{l}\text { Critical thermal maxima } \\
\quad\left({ }^{\circ} \mathrm{C}\right)\end{array}$ & $\begin{array}{l}\text { Plasticity } \\
\text { Acclimation } \\
\text { Error }\end{array}$ & $\begin{array}{l}1 \\
2\end{array}$ & $\begin{array}{l}7.117 \\
0.352\end{array}$ & $\begin{array}{r}2.19 \\
55.00\end{array}$ & $\begin{array}{l}0.322 \\
0.115\end{array}$ & $\begin{array}{r}22.100 \\
3.048\end{array}$ & $\begin{array}{r}<0.05 \\
0.056\end{array}$ & $\begin{array}{r}66.8 \\
4.1 \\
29.2\end{array}$ \\
\hline $\begin{array}{l}\text { Critical thermal minima } \\
\quad\left({ }^{\circ} \mathrm{C}\right)\end{array}$ & $\begin{array}{l}\text { Plasticity } \\
\text { Acclimation } \\
\text { Error }\end{array}$ & $\begin{array}{l}1 \\
2\end{array}$ & $\begin{array}{r}2.408 \\
40.442\end{array}$ & $\begin{array}{r}2.00 \\
56.00\end{array}$ & $\begin{array}{r}35.975 \\
0.240\end{array}$ & $\begin{array}{r}0.067 \\
168.406\end{array}$ & $\begin{array}{c}0.820 \\
<0.0001\end{array}$ & $\begin{array}{c}0 \\
91.8 \\
8.2\end{array}$ \\
\hline $\begin{array}{l}\text { Desiccation rate } \\
\qquad\left(\mathrm{mg} \mathrm{H}_{2} \mathrm{O} \mathrm{h}^{-1}\right)^{\mathrm{a}}\end{array}$ & $\begin{array}{l}\text { Plasticity } \\
\text { Acclimation } \\
\text { Error }\end{array}$ & $\begin{array}{l}1 \\
2\end{array}$ & $\begin{array}{l}0.146 \\
0.119\end{array}$ & $\begin{array}{r}2.33 \\
43.00\end{array}$ & $\begin{array}{l}0.080 \\
0.016\end{array}$ & $\begin{array}{l}1.825 \\
7.624\end{array}$ & $\begin{array}{r}0.293 \\
<0.005\end{array}$ & $\begin{array}{l}15.5 \\
30.1 \\
54.4\end{array}$ \\
\hline $\begin{array}{l}\text { Standard metabolic rate } \\
\quad\left(\log _{10} \mu \mathrm{lCO}_{2} \mathrm{~h}^{-1}\right)^{\mathrm{b}}\end{array}$ & $\begin{array}{l}\text { Plasticity } \\
\text { Acclimation } \\
\text { Error }\end{array}$ & $\begin{array}{l}1 \\
2\end{array}$ & $\begin{array}{l}0.066 \\
0.122\end{array}$ & $\begin{array}{r}2.08 \\
23.00\end{array}$ & $\begin{array}{l}0.087 \\
0.006\end{array}$ & $\begin{array}{r}0.757 \\
21.275\end{array}$ & $\begin{array}{c}0.473 \\
<0.0001\end{array}$ & $\begin{array}{c}0 \\
74.6 \\
25.4\end{array}$ \\
\hline
\end{tabular}

Summary of nested (hierarchical) analyses of variance; plasticity and acclimation were categorised as random factors.

MS, mean squares, d.f., degrees of freedom.

${ }^{a}$ Covarying for dry body mass $(P<0.05)$.

${ }^{\mathrm{b}}$ Covarying for mean experimental body mass $(P<0.05)$. 
Table 2. Testing for an effect of acclimation (treatment temperature $21,29^{\circ} \mathrm{C}$ ) and experimental plasticity on physiological traits of climatic stress resistance in adult Glossina pallidipes (Diptera, Glossinidae)

\begin{tabular}{|c|c|c|c|c|c|c|c|c|}
\hline Physiological trait & Effect & d.f. & MS & d.f. error & MS error & $F$-ratio & $P$ & $\begin{array}{l}\text { \% variance } \\
\text { explained }\end{array}$ \\
\hline $\begin{array}{l}\text { Critical thermal maxima } \\
\quad\left({ }^{\circ} \mathrm{C}\right)\end{array}$ & $\begin{array}{l}\text { Acclimation } \\
\text { Plasticity } \\
\text { Error }\end{array}$ & $\begin{array}{l}1 \\
4\end{array}$ & $\begin{array}{l}0.041 \\
2.077\end{array}$ & $\begin{array}{r}3.89 \\
73.00\end{array}$ & $\begin{array}{l}2.493 \\
0.164\end{array}$ & $\begin{array}{r}0.016 \\
12.665\end{array}$ & $\begin{array}{c}0.904 \\
<0.0001\end{array}$ & $\begin{array}{c}0 \\
48.7 \\
51.3\end{array}$ \\
\hline $\begin{array}{l}\text { Critical thermal minima } \\
\quad\left({ }^{\circ} \mathrm{C}\right)\end{array}$ & $\begin{array}{l}\text { Acclimation } \\
\text { Plasticity } \\
\text { Error }\end{array}$ & $\begin{array}{l}1 \\
4\end{array}$ & $\begin{array}{r}100.352 \\
3.114\end{array}$ & $\begin{array}{r}3.90 \\
74.00\end{array}$ & $\begin{array}{l}3.688 \\
0.245\end{array}$ & $\begin{array}{l}27.213 \\
12.725\end{array}$ & $\begin{array}{l}<0.01 \\
<0.0001\end{array}$ & $\begin{array}{r}83.6 \\
7.9 \\
8.5\end{array}$ \\
\hline $\begin{array}{l}\text { Desiccation rate } \\
\qquad\left(\mathrm{mg} \mathrm{H}_{2} \mathrm{O} \mathrm{h}^{-1}\right)^{\mathrm{a}}\end{array}$ & $\begin{array}{l}\text { Acclimation } \\
\text { Plasticity } \\
\text { Error }\end{array}$ & $\begin{array}{l}1 \\
4\end{array}$ & $\begin{array}{l}0.287 \\
0.196\end{array}$ & $\begin{array}{r}3.89 \\
73.00\end{array}$ & $\begin{array}{l}0.231 \\
0.016\end{array}$ & $\begin{array}{r}1.241 \\
12.251\end{array}$ & $\begin{aligned} & 0.329 \\
< & 0.0001\end{aligned}$ & $\begin{array}{r}4.4 \\
46.7 \\
48.9\end{array}$ \\
\hline $\begin{array}{l}\text { Standard metabolic rate } \\
\qquad\left(\log _{10} \mu l \mathrm{CO}_{2} \mathrm{~h}^{-1}\right)^{\mathrm{b}}\end{array}$ & $\begin{array}{l}\text { Acclimation } \\
\text { Plasticity } \\
\text { Error }\end{array}$ & $\begin{array}{l}1 \\
4\end{array}$ & $\begin{array}{l}0.211 \\
0.046\end{array}$ & $\begin{array}{r}3.85 \\
33.00\end{array}$ & $\begin{array}{l}0.051 \\
0.008\end{array}$ & $\begin{array}{l}4.137 \\
6.045\end{array}$ & $\begin{array}{r}0.114 \\
<0.001\end{array}$ & $\begin{array}{l}36.4 \\
29.0 \\
34.6\end{array}$ \\
\hline
\end{tabular}

Summary of nested (hierarchical) analyses of variance; plasticity and acclimation were categorised as random factors.

MS, mean squares, d.f., degrees of freedom.

${ }^{a}$ Covarying for dry body mass $(P<0.05)$.

${ }^{\mathrm{b}}$ Covarying for mean experimental body mass $(P<0.05)$.

of variance between plasticity type and treatment temperature (Table 2).

\section{Discussion}

The effects of treatment temperature on the traits investigated in $G$. pallidipes here are largely similar to what has been found in other investigations of insects. In the case of thermal tolerances, acclimation effects were more pronounced for $T_{\text {crit,min }}$ than for $T_{\text {crit,max }}$, as has been found in several other studies examining acclimation (Klok and Chown,

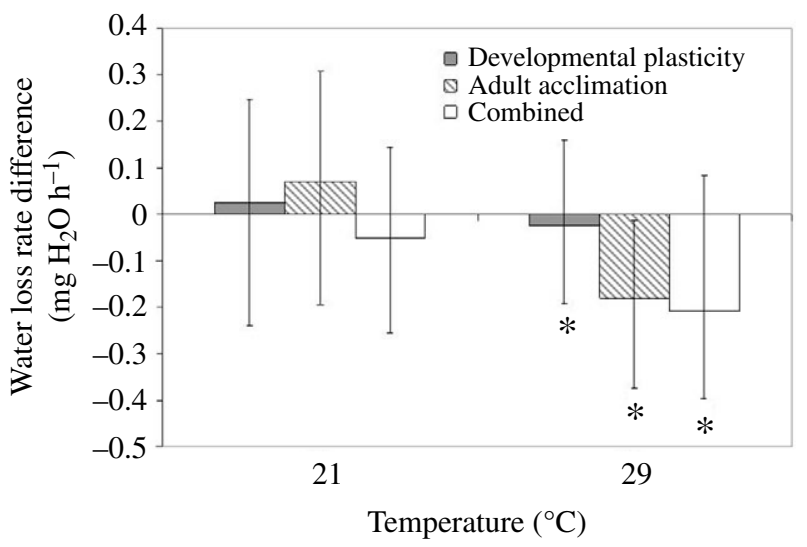

Fig. 4. Relative change in mean water loss rate for developmental plasticity, adult acclimation and combined plasticity groups within the acclimation temperature treatments expressed as change from the mean of the $25^{\circ} \mathrm{C}$ group. Asterisks indicate a significant effect of the acclimation relative to the $25^{\circ} \mathrm{C}$ group by GLM (covariate: dry body mass; $P<0.05$ ). Lower and upper error bars represent minimum and maximum values, respectively.
2003; Slabber and Chown, 2005) or acclimatization (Hoffmann et al., 2005b) effects on thermal limits. Although a more pronounced acclimation effect on lower than on upper limits is not universal [e.g. the converse has been found the caterpillars of the moth Embryonopsis halticella (Klok and Chown, 1998)], it does seem to be typical of most ectotherms (Kingsolver and Huey, 1998). In insects, greater variation in lower than in upper thermal tolerances is typical not only of acclimation responses, but also of intra- and interspecific

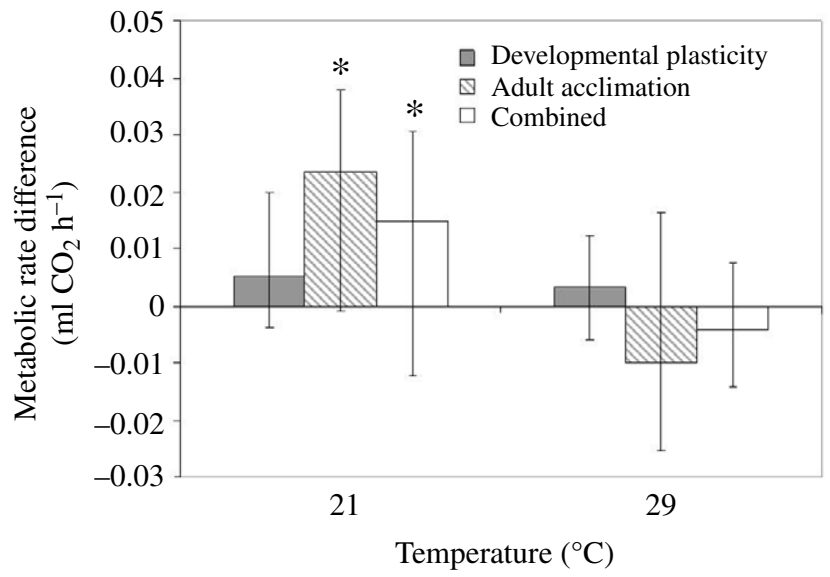

Fig. 5. Relative change in mean metabolic rate as indicated by $\mathrm{CO}_{2}$ production for developmental plasticity, adult acclimation and combined plasticity groups within the acclimation temperature treatments, expressed as change from the mean of the $25^{\circ} \mathrm{C}$ group. Asterisks indicate a significant effect of the acclimation relative to the $25^{\circ} \mathrm{C}$ group by GLM (covariate: mean experimental body mass; $P<0.05$ ). Lower and upper error bars represent minimum and maximum values, respectively. 
geographic variation in thermal limits, and in the responses of these limits to selection (Addo-Bediako et al., 2000; Chen et al., 1990; Chown, 2001; Gaston and Chown, 1999; Gilchrist et al., 1997; Hercus et al., 2000; Hoffmann et al., 1997; Kimura, 2004; Stanley et al., 1980; Terblanche et al., 2005b).

Increases in metabolic rate of the $G$. pallidipes adults with adult exposure to low temperature seems to be typical of this group of tsetse flies because it has also been found in Glossina morsitans. Exposure of adult G. moristans to $29^{\circ} \mathrm{C}$ had little effect on metabolic rate relative to adults held at $24^{\circ} \mathrm{C}$, but exposure to $19^{\circ} \mathrm{C}$ resulted in a significant increase in metabolic rate across a wide range of test temperatures (Terblanche et al., 2005a). Increases of metabolic rate in insects exposed to low temperatures are not uncommon (reviewed in Addo-Bediako et al., 2002; Chown and Gaston, 1999). However, the causes, consequences and likely significance of such whole organismal metabolic upregulation remain controversial and poorly investigated (Chown et al., 2003; Clarke, 2003; Hodkinson, 2003). Why metabolic rate should increase following exposure to a relatively low temperature in tsetse adults is not clear, but might contribute to the absence of this species (and $G$. morsitans) from low temperature areas. Elevated metabolic rates will result in increased use of lipid reserves, lower tolerance of starvation, and increased pressure for foraging, all of which are likely to enhance the chances of mortality (Rajagopal and Bursell, 1966), likely limiting the ability of the flies to survive in low temperature environments (though a lack of pupal development is also important for restricting flies to warmer areas; for reviews, see Hargrove, 2004; Rogers and Robinson, 2004).

Perhaps more unusual than the responses of the other traits to acclimation was the change in desiccation rate in response to the temperature treatments. Previous studies have shown strong responses of insect desiccation rate to changes in relative humidity (e.g. Gibbs et al., 2003; Hoffmann, 1990). However, responses of water balance parameters to different temperature regimes are more variable. In some cases treatment temperature has elicited either no response in water balance-related traits (Terblanche et al., 2005b), or a response that is expressed in some traits but not others, such as cuticular hydrocarbon profile changes but no alteration of water loss rates in cactophilic Drosophila (Gibbs et al., 1998; see also Cloudsley-Thompson, 1969). In others, pronounced responses in desiccation rate have been found. This is true of $D$. melanogaster from the east coast of Australia, where in several populations in response to summer acclimation temperatures, individuals showed greater desiccation resistance than flies exposed to constant or winter temperatures (Hoffmann et al., 2005b). Similar declines in desiccation resistance with increasing treatment temperature have also been found for $D$. takahashii and D. nepalensis (Parkash et al., 2005). Here, we found that when exposed to $29^{\circ} \mathrm{C}$, either as adults or as pupae, adult $G$. pallidipes had significantly reduced rates of water loss compared to flies held at $21^{\circ} \mathrm{C}$ or $25^{\circ} \mathrm{C}$ (and similar to results described in Terblanche et al., in press). Neither the ultimate, nor proximate causes of this change have been fully investigated. It seems likely that in the former case a reduction in desiccation rate at high temperatures should increase survival, given that high temperatures can be associated with low water availability in the habitats occupied by these flies. Indeed, inter-population comparisons of $G$. pallidipes in Kenya have shown that populations from drier areas tend to have the lower water loss rates than those from moister areas (Terblanche et al., in press). How the acclimation or interpopulation differences are effected mechanistically has not been well studied, but differences in the amount and composition of cuticular lipids might be significant, as has been found in other species (Gibbs et al., 1991; Rourke, 2000). Preliminary studies in this species have indicated that variation in cuticular hydrocarbon profiles and desiccation rates can occur among populations; however, desiccation rates in these flies are not correlated with cuticular lipid mass (i.e. quantity) (R. Jurenka, G. Marquez, J. Odera, J. Terblanche, C. Klok, S. Chown and E. Krafsur, unpublished data).

Whilst the extent of the acclimation responses varied among traits, several generalizations can be made about the effects of plasticity type on the traits measured in the adults. Responses to treatment temperature showed an asymmetric effect across all responsive plasticity types, with either the low treatment temperature or the high treatment temperature having a significant effect, but responses to both were found only for

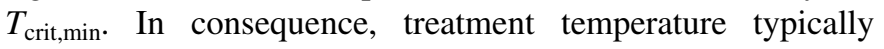
explained less than half of the variance in the measured traits, except in the case of $T_{\text {crit,min, }}$, where it accounted for more than $80 \%$ of the variance. However, the symmetric $T_{\text {crit,min }}$ response was found only for the combined plasticity treatment, and in this case appeared to comprise a response to the $21^{\circ} \mathrm{C}$ treatment in the adults, and a response to the $29^{\circ} \mathrm{C}$ treatment in the pupae, but not vice versa. This finding deserves further exploration. Nonetheless, strong opposing responses to high and low temperature treatments for lower thermal limits have been found in several other studies, though typically these examined acclimation effects on a single stage only (e.g. Ayrinhac et al., 2004; Hoffmann et al., 2005b; Klok and Chown, 2003; Slabber and Chown, 2005; Terblanche et al., 2005b; Zeilstra and Fischer, 2005). Likewise, asymmetric or threshold effects of treatment temperature have previously been recorded for $T_{\text {crit,max }}$ (Hoffmann et al., 2005b; Klok and Chown, 1998; Slabber and Chown, 2005), metabolic rate (Hoffmann, 1985; Terblanche et al., 2005a) and desiccation rate (Rourke, 2000).

By contrast, plasticity type usually accounted for substantial proportions of the variation in the response of the traits to acclimation. Developmental plasticity following the $29^{\circ} \mathrm{C}$ temperature treatments was significant and irreversible for $T_{\text {crit,min }}$ and desiccation rate, but the pupal treatment was either reversed or had little effect following the $21^{\circ} \mathrm{C}$ treatment for these traits and for both temperature treatments in the other traits. The absence of reversibility in $T_{\text {crit,min }}$ following exposure to $29^{\circ} \mathrm{C}$ is unlike the situation in Lycaena tityrus, in which lower thermal limits that change within the pupal stage are typically reversible in the adults (Zeilstra and Fischer, 2005). No other work has examined the effects of 


\section{Plasticity in tsetse flies 1071}

developmental plasticity on desiccation rate in insects, but clearly it is significant. Developmental plasticity is known from a wide variety of other traits, e.g. morphological, behavioural, locomotion performance (Atkinson, 1996; Crill et al., 1996; Nijhout, 2003; Sheeba et al., 2002), and generally is assumed to be fixed in the adult stage (e.g. Gibert et al., 2000; discussed in Wilson and Franklin, 2002). Although early work assumed that such plasticity would be beneficial, most recent studies have shown that this is rarely the case (for a discussion, see Huey et al., 1999; Wilson and Franklin, 2002). The present design did not enable us to fully explore this hypothesis, though clearly the responses shown by $T_{\text {crit,min }}$ and desiccation rate could initially be considered beneficial, given that vapour pressure deficit would increase at higher temperatures (for a given quantity of water in the air) (Addo-Bediako et al., 2001), and that a trade-off between the extent of lower thermal limits and starvation resistance has been found (Hoffmann et al., 2005a).

Adult acclimation effects were most common following low temperature exposures, although for desiccation rate it was only the high temperature exposure that had an effect. Although the time course of the persistence of changes in physiological tolerances has not yet been investigated, other work on the same species has shown that plasticity in $T_{\text {crit,min }}$ is reversible within 10 days (Terblanche et al., in press). The generality of these findings for other traits of physiological tolerance in this and other insect species warrants further attention. These findings are in keeping with what has been found in many other studies (reviewed in Spicer and Gaston, 1999; see also Wilson and Franklin, 2002), and confirm the notion that adult acclimation is typically reversible, while developmental plasticity is not (Piersma and Drent, 2003). What was perhaps most significant is that the combined plasticity treatments did not seem to have noticeable additive effects. Rather, the extent of the response following the combined treatments was either quite similar to the pupal or adult response following exposure, or in the case of the response of critical thermal limits to the low temperatures, seemed to have a negative effect on tolerance. What the basis for this negative interaction might be is not clear. However, it is known that basal and induced cold tolerance responses are linked in some species (Chown and Nicolson, 2004).

In conclusion, this study has shown that the stage at which acclimation takes place has significant, though often different, effects on several adult traits that are likely to modify environmental effects on populations of $G$. pallidipes. These show that it is not only important to distinguish between developmental plasticity and adult acclimation (Wilson and Franklin, 2002; Piersma and Drent, 2003) and consider possible interactions among them, but also to consider the direction of the responses and their significance from a lifehistory perspective (Fischer et al., 2003).

We thank Larissa Heyns for laboratory assistance and the IAEA Entomology Unit at Seibersdorf, in particular Andrew Parker, for flies and rearing equipment. We are grateful to
Jaco Klok who performed the critical thermal limit assessments. Elliot Krafsur, Ulrike Irlich, Peter le Roux, Elrike Marais, and two anonymous referees provided useful and constructive comments on an earlier version. This work was funded by an NIH grant AI-52456 to E. S. Krafsur.

\section{References}

Addo-Bediako, A., Chown, S. L. and Gaston, K. J. (2000). Thermal tolerance, climatic variability and latitude. Proc. R. Soc. Lond. B 267, 739745.

Addo-Bediako, A., Chown, S. L. and Gaston, K. J. (2001). Revisiting water loss in insects: a large scale view. J. Insect Physiol. 47, 1377-1388.

Addo-Bediako, A., Chown, S. L. and Gaston, K. J. (2002). Metabolic cold adaptation in insects: a large-scale perspective. Funct. Ecol. 16, 332-338.

Atkinson, D. (1996). Ectotherm life-history responses to developmental temperature. In Animals and Temperature. Phenotypic and Evolutionary Adaptation (ed. I. A. Johnston and A. F. Bennett), pp. 183-204. Cambridge: Cambridge University Press.

Ayrinhac, A., Debat, V., Gibert, P., Kister, A.-G., Legout, H., Moreteau, B., Vergilino, R. and David, J. R. (2004). Cold adaptation in geographical populations of Drosophila melanogaster: phenotypic plasticity is more important than genetic variability. Funct. Ecol. 18, 700-706.

Berrigan, D. and Scheiner, S. M. (2004). Modeling the evolution of phenotypic plasticity. In Phenotypic Plasticity: Functional and Conceptual Approaches (ed. T. J. De Witt and S. M. Scheiner). New York: Oxford University Press.

Brady, J. (1988). Circadian ontogeny in the tsetse fly: A permanent major phase change after the first feed. J. Insect Physiol. 34, 743-749.

Bursell, E. (1957). Spiracular control of water loss in the tsetse fly. Proc. $R$. Entomol. Soc. A 32, 21-29.

Bursell, E. and Taylor, P. (1980). An energy budget for Glossina (Diptera: Glossinidae). B. Entomol. Res. 70, 187-196.

Bursell, E., Billing, K. C., Hargrove, J. W., McCabe, C. T. and Slack, E. (1974). Metabolism of the bloodmeal in tsetse flies. Acta Trop. 31, 297-320.

Chen, C.-P., Lee, R. E., Jr and Denlinger, D. L. (1990). A comparison of the responses of tropical and temperate flies (Diptera: Sarcophagidae) to cold and heat stress. J. Comp. Physiol. 160, 543-547.

Chown, S. L. (2001). Physiological variation in insects: hierarchical levels and implications. J. Insect Physiol. 47, 649-660.

Chown, S. L. and Gaston, K. J. (1999). Exploring links between physiology and ecology at macro scales: the role of respiratory metabolism in insects. Biol. Rev. 74, 87-120.

Chown, S. L. and Nicolson, S. W. (2004). Insect Physiological Ecology. Mechanisms and Patterns. Oxford: Oxford University Press.

Chown, S. L., Addo-Bediako, A. and Gaston, K. J. (2002). Physiological variation in insects: large-scale patterns and their implications. Comp. Biochem. Physiol. 131B, 587-602.

Chown, S. L., Addo-Bediako, A. and Gaston, K. J. (2003). Physiological diversity: listening to the large-scale signal. Funct. Ecol. 17, 568-572.

Clarke, A. (2003). Costs and consequences of evolutionary temperature adaptation. Trends Ecol. Evol. 18, 573-581.

Cloudsley-Thompson, J. L. (1969). Acclimation, water and temperature relations of the woodlice Metoponorthus pruinosus and Periscyphis jannonei in the Sudan. J. Zool. 158, 267-276.

Crill, W. D., Huey, R. B. and Gilchrist, G. W. (1996). Within- and betweengeneration effects of temperature on the morphology and physiology of Drosophilia melanogaster. Evolution 50, 1205-1218.

Edney, E. B. and Barrass, R. (1962). The body temperature of the tsetse fly, Glossina morsitans Westwood (Diptera, Muscidae). J. Insect Physiol. 8, 469-481.

Fischer, K., Eenhorn, E., Bot, A. N. M., Brakefield, P. M. and Zwaan, B. J. (2003). Cooler butterflies lay larger eggs: developmental plasticity versus acclimation. Proc. R. Soc. Lond. B 270, 2051-2056.

Gaston, K. J. and Chown, S. L. (1999). Elevation and climatic tolerance: a test using dung beetles. Oikos 86, 584-590.

Gibbs, A., Mousseau, T. A. and Crowe, J. H. (1991). Genetic and acclimatory variation in biophysical properties of insect cuticle lipids. Proc. Natl. Acad. Sci. USA 88, 7257-7260.

Gibbs, A. G., Louie, A. K. and Ayala, J. A. (1998). Effects of temperature on cuticular lipids and water balance in a desert Drosophila: is thermal acclimation beneficial? J. Exp. Biol. 201, 71-80. 
Gibbs, A. G., Fukuzato, F. and Matzkin, L. M. (2003). Evolution of water conservation mechanisms in Drosophila. J. Exp. Biol. 206, 1183-1192.

Gibert, P., Moreteau, B. and David, J. R. (2000). Developmental constraints on an adaptive plasticity: reaction norms of pigmentation in adult segments of Drosophila melanogaster. Evol. Dev. 2, 249-260.

Gibert, P., Huey, R. B. and Gilchrist, G. W. (2001). Locomotor performance of Drosophila melanogaster: Interactions among developmental and adult temperatures, age, and geography. Evolution 55, 205-209.

Gilchrist, G. W. and Huey, R. B. (2001). Parental and developmental temperature effects on the thermal dependence of fitness in Drosophila melanogaster. Evolution 55, 209-214.

Gilchrist, G. W., Huey, R. B. and Partridge, L. (1997). Thermal sensitivity of Drosophila melanogaster: evolutionary responses of adults and eggs to laboratory natural selection at different temperatures. Physiol. Zool. 70, 403 414.

Gooding, R. H., Feldmann, U. and Robinson, A. S. (1997). Care and maintenance of tsetse colonies. In The Molecular Biology of Insect Disease Vectors (ed. J. M. Crampton, C. B. Beard and C. Louis), pp. 41-55. London: Chapman \& Hall.

Hargrove, J. W. (2004). Tsetse population dynamics. In The Trypanosomiases (ed. I. Maudlin, P. H. Holmes and M. A. Miles), pp. 113138. Wallingford: CABI Publishing.

Helmuth, B., Kingsolver, J. G. and Carrington, E. (2005). Biophysics, physiological ecology, and climate change: Does mechanism matter? Annu. Rev. Physiol. 67, 177-201.

Hercus, M. J., Berrigan, D., Blows, M. W., Magiafoglou, A. and Hoffmann, A. A. (2000). Resistance to temperature extremes between and within life cycle stages in Drosophila serrata, D. birchii and their hybrids: intraspecific and interspecific comparisons. Biol. J. Linn. Soc. Lond. 71 403-416.

Hochachka, P. W. and Somero, G. N. (2002). Biochemical Adaptation. Mechanism and Process in Physiological Evolution. New York: Oxford University Press.

Hodkinson, I. D. (2003). Metabolic cold adaptation in arthropods: a smallerscale perspective. Funct. Ecol. 17, 562-567.

Hoffmann, A. A. (1990). Acclimation for desiccation resistance in Drosophila melanogaster and the association between acclimation responses and genetic variation. J. Insect Physiol. 36, 885-891.

Hoffmann, A. A., Dagher, H., Hercus, M. and Berrigan, D. (1997). Comparing different measures of heat resistance in selected lines of Drosophila melanogaster. J. Insect Physiol. 43, 393-405.

Hoffmann, A. A., Hallas, R., Anderson, A. R. and Telonis-Scott, M. (2005a). Evidence for a robust sex-specific trade-off between cold resistance and starvation resistance in Drosophila melanogaster. J. Evol. Biol. 18, 804 810.

Hoffmann, A. A., Shirrifs, J. and Scott, M. (2005b). Relative importance of plastic vs genetic factors in adaptive differentiation: geographical variation for stress resistance in Drosophila melanogaster from eastern Australia. Funct. Ecol. 19, 222-227.

Hoffmann, K. H. (1985). Metabolic and enzyme adaptation to temperature. In Environmental Physiology and Biochemistry of Insects (ed. K. H Hoffmann), pp. 1-32. Berlin: Springer-Verlag.

Huey, R. B., Berrigan, D., Gilchrist, G. W. and Herron, J. C. (1999). Testing the adaptive significance of acclimation: a strong inference approach. Am. Zool. 39, 323-336.

Kimura, M. T. (2004). Cold and heat tolerance of drosopholid flies with reference to their latitudinal distributions. Oecologia 140, 442-449.

Kingsolver, J. G. and Huey, R. B. (1998). Evolutionary analyses of morphological and physiological plasticity in thermally variable environments. Am. Zool. 38, 545-560.

Klok, C. J. and Chown, S. L. (1998). Interactions between desiccation resistance, host-plant contact and the thermal biology of a leaf-dwelling subAntarctic caterpillar, Embryonopsis halticella (Lepidoptera: Yponomeutidae). J. Insect Physiol. 44, 615-628.

Klok, C. J. and Chown, S. L. (2003). Resistance to temperature extremes in sub-Antarctic weevils: interspecific variation, population differentiation and acclimation. Biol. J. Linn. Soc. Lond. 78, 401-414.

Klok, C. J., Sinclair, B. J. and Chown, S. L. (2004). Upper thermal tolerance and oxygen limitation in terrestrial arthropods. J. Exp. Biol. 207, 2361-2370.

Krafsur, E. S. and Wohlford, D. L. (1999). Breeding structure of Glossina pallidipes populations evaluated by mitochondrial variation. J. Hered. $\mathbf{9 0}$, 635-642.

Kyorku, C. and Brady, J. (1993). A free-running bimodal circadian rhythm in the tsetse fly Glossina longipennis. J. Insect Physiol. 40, 63-67.
Leroi, A. M., Bennett, A. F. and Lenski, R. E. (1994). Temperature acclimation and competitive fitness: an experimental test of the beneficial acclimation assumption. Proc. Natl. Acad. Sci. USA 91, 1917-1921.

Lutterschmidt, W. I. and Hutchison, V. H. (1997). The critical thermal maximum: data to support the onset of spasms as the definitive end point Can. J. Zool. 75, 1553-1560.

Maudlin, I., Holmes, P. H. and Miles, M. A. (2004). The Trypanosomiases. Wallingford: CABI Publishing.

Nijhout, H. F. (2003). Development and evolution of adaptive polyphenisms. Evol. Dev. 5, 9-18.

Nunney, L. and Cheung, W. (1997). The effect of temperature on body size and fecundity in female Drosophila melanogaster: evidence for adaptive plasticity. Evolution 51, 1529-1535.

Parkash, R., Tyagi, P. K., Sharma, I. and Rajpurohit, S. (2005). Adaptations to environmental stress in altitudinal populations of two Drosophila species. Physiol. Entomol. 30, 353-361

Piersma, T. and Drent, J. (2003). Phenotypic flexibility and the evolution of organismal design. Trends Ecol. Evol. 18, 228-233.

Price, T. D., Qvarnström, A. and Irwin, D. E. (2003). The role of phenotypic plasticity in driving genetic evolution. Proc. R. Soc. Lond. B 270, 14331440.

Prosser, C. L. (1986). Adaptational Biology. Molecules to Organisms. New York: John Wiley \& Sons

Rajagopal, P. K. and Bursell, E. (1966). The respiratory metabolism of resting tsetse flies. J. Insect Physiol. 12, 287-297.

Rogers, D. J. and Robinson, T. P. (2004). Tsetse distribution. In The Trypanosomiases (ed. I. Maudlin, P. H. Holmes and M. A. Miles), pp. 139180. Wallingford: CABI Publishing.

Rourke, B. C. (2000). Geographic and altitudinal variation in water balance and metabolic rate in a California grasshopper, Melanoplus sanguinipes. $J$. Exp. Biol. 203, 2699-2712.

Scheiner, S. M. (1993). Genetics and evolution of phenotypic plasticity. Аnпи. Rev. Ecol. Syst. 24, 35-68.

Sheeba, V., Chandrashekaran, M. K., Joshi, A. and Sharma, V. K. (2002). Developmental plasticity of the locomotor activity rhythm of Drosophila melanogaster. J. Insect Physiol. 48, 25-32.

Sibly, R. M., Winokus, L. and Smith, R. H. (1997). Interpopulation variation in phenotypic plasticity in the speckled wood butterfly, Pararge aegeria. Oikos 78, 323-330.

Sinclair, B. J. and Chown, S. L. (2005). Deleterious effects of repeated cold exposure in a freeze-tolerant sub-Antarctic caterpillar. J. Exp. Biol. 208, 869-879.

Slabber, S. and Chown, S. L. (2005). Differential responses of thermal tolerance to acclimation in the sub-Antarctic rove beetle Halmaeusa atriceps. Physiol. Entomol. 30, 195-204.

Somero, G. N. (2005). Linking biogeography to physiology: Evolutionary and acclimatory adjustments of thermal limits. Front. Zool. 2, doi: 10.1186/1742-9994-2-1.

Sokal, R. R. and Rohlf, F. J. (1995). Biometry. The Principles and Practice of Statistics in Biological Research (3rd edn.). New York: W. H. Freeman.

Spicer, J. I. and Gaston, K. J. (1999). Physiological diversity and its ecological implications. Oxford: Blackwell Science.

Stanley, S. M., Parsons, P. A., Spence, G. A. and Weber, L. (1980). Resistance of species of the Drosophila melanogaster subgroup to environmental extremes. Aust. J. Zool. 28, 413-421.

Terblanche, J. S., Klok, C. J. and Chown, S. L. (2004). Metabolic rate variation in Glossina pallidipes (Diptera: Glossinidae): gender, ageing and repeatability. J. Insect Physiol. 50, 419-428.

Terblanche, J. S., Klok, C. J. and Chown, S. L. (2005a). Temperaturedependence of metabolic rate in Glossina morsitans morsitans (Diptera, Glossinidae) does not vary with gender, age, feeding, pregnancy or acclimation. J. Insect Physiol. 51, 861-870.

Terblanche, J. S., Sinclair, B. J., Klok, C. J., McFarlane, M. L. and Chown, S. L. (2005b). The effects of acclimation on thermal tolerance, desiccation resistance and metabolic rate in Chirodica chalcoptera (Coleoptera: Chrysomelidae). J. Insect Physiol. 51, 1013-1023.

Terblanche, J. S., Klok, C. J., Krafsur, E. S. and Chown, S. L. (in press) Phenotypic flexibility and geographic variation in thermal tolerance and water loss of the tsetse fly Glossina pallidipes (Diptera: Glossinidae) implications for distribution modelling. Am. J. Trop. Med. Hyg.

Thomson, L. J., Robinson, M. and Hoffmann, A. A. (2001). Field and laboratory evidence for acclimation without costs in an egg parasitoid. Funct. Ecol. 15, 217-221. 


\section{Plasticity in tsetse flies 1073}

Tracy, R. L. and Walsberg, G. E. (2001). Developmental and acclimatory contributions to water loss in a desert rodent: investigating the time-course of adaptive change. J. Comp. Physiol. B 171, 669-679.

Wilson, R. S. and Franklin, C. E. (2002). Testing the beneficial acclimation hypothesis. Trends Ecol. Evol. 17, 66-70.

Winston, P. W. and Bates, D. H. (1960). Saturated solutions for the control of humidity in biological research. Ecology 41, 232-237.

Woods, H. A. (1999). Patterns and mechanisms of growth of fifth-instar Manduca sexta caterpillars following exposure to low- or high-protein food during early instars. Physiol. Biochem. Zool. 72, 445-454.
Woods, H. A. and Harrison, J. F. (2001). The beneficial acclimation hypothesis versus acclimation of specific traits: physiological change in water-stressed Manduca sexta caterpillars. Physiol. Biochem. Zool. 74, 3244.

Zamudio, K. R., Huey, R. B. and Crill, W. D. (1995). Bigger isn't always better: body size, temperature and male territorial success in Drosophila melanogaster. Anim. Behav. 49, 671-677.

Zeilstra, I. and Fischer, K. (2005). Cold tolerance in relation to developmental and adult temperature in a butterfly. Physiol. Entomol. 30, 92-95. 